general readers will be familiar with the nature of babeiasis, black head of turkeys, or even coccidiosis in poultry, while the veterinarian might equally well be interested to know how trichomonas and giardia affect human beings. This work is of a monumental character and Dr. Findlay must be congratulated on the industry of his compilation. With the continuous rapid development of this vast branch of medicine it is difficult to see how the work could have been compressed into smaller compass.

\section{THE COMMON DISEASES OF THE SKIN}

By R. CRANSTON Low, M.D., F.R.C.P.E., F.R.S.E., and G. A. Grant Peterkin, M.B.E., M.B., F.R.C.P.ED. 4th edition. Pp. $x+282$, with 139 illustrations. Edinburgh : Oliver \& Boyd, Ltd. I950. 2 is.

Cranston Low's textbook has gained a secure place in the affections of Scottish students. This edition, prepared with the help of Dr. Peterkin before the author's death, retains the general structure of its predecessors. It has been brought up to date to include the considerable advances of the last ten years, and new illustrations have been added.

It is never easy to review a handbook of dermatology; if it is to be primarily for students and general practitioners some limitation of scope and a dogmatic approach may be excused. It is only fair to say that the authors recognize this and acknowledge it. But the reviewer feels that such an approach, to be justified, should not be employed in highly controversial issues. The septic focus and toxic absorption from the bowel, as causes of various skin affections, are given a prominence outweighing the evidence in their favour. On the other hand, out of 92 lines given to the treatment of lupus vulgaris, only six are given to calciferolwhich is generally considered to be the method of choice.

In practical matter the book is often admirable, stressing the importance of detail in everyday techniques; many would differ from the authors, however, in their acceptance of soap and water in eczematous states.

The format and choice of type is excellent and the plain photographs useful and clear. There are also six colour-plates. The formulary given at the end contains all the most useful applications used in practice.

\section{THE SCOURGE OF RHEUMATISM}

Report of a Conference held by the British Rheumatic Association. Pp. 85. London : William Heinemann. 1950. 5s.

This little book presents some of the views expressed at a meeting of the British Rheumatic Association, which is a body primarily organized by a group of rheumatic patients for the welfare of rheumatic sufferers. The views expressed are from laymen, rheumatism and physical medicine specialists and social workers of various kinds.
The booklet is of interest to the rheumatic patient, but is not sufficiently scientific to be of $\frac{3}{\Phi}$ great value to medical men. The medical aspect is $\stackrel{\varnothing}{\varrho}$ dealt with only in general principle and super..ficially.

To those concerned in the welfare of rheumatic $\frac{\vec{F}}{\stackrel{\vec{P}}{+}}$ patients, however, it should be of much interest, $\frac{}{c}$ showing the facilities available medically, socially and industrially for the rheumatic patient.

\section{PENICILLIN : ITS PRACTICAL APPLICATION}

By Prof. Sir Alexander Fleming, M.B., B.S., $\stackrel{\overrightarrow{0}}{-}$ F.R.C.P., F.R.C.S., F.R.S. 2nd Edition. Pp. $\vec{\omega}$ xiii +491 , with $6_{3}$ figures. London : Butterworth and Co., Ltd. 1949. 3os.

The scope and methods of penicillin treatment are changing constantly so that the appearance of a second edition of this book is very welcome. The $\dot{\omega}$ chapters on the history, chemistry, bacteriology and practical applications are written by experts in each field, under the editorship of Prof. Fleming. + Though this involves some repetition, it also shows

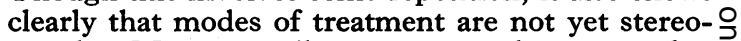
typed. Most contributors agree, however, that $\rightarrow$ procaine penicillin is superseding other prepara- 0 tions. New chapters have been added on drug sensitivity and on the newer antibiotics. The bowio is an invaluable guide, is well produced and freety illustrated.

\section{MEDICAL JURISPRUDENCE AND TOXICOLOGY}

By John Glaister, J.P., D.Sc., M.D., F.R.S.E. 9th Edition. Pp. xi +755 , with 234 illustrations, $\mathbb{D}$ 88 in colour. Edinburgh : E. and S. Livingstone. 1950. $35 \mathrm{~s}$.

The ninth edition of Glaister's well-known textbook again increases its compass. It continues to attract the student by its authority, its diversity of fresh illustrations (234 plates are now included in $\frac{}{3}$ the 755 page text) and its high standard of production, whilst causing some misgiving by its increasing size. It undoubtedly succeeds in providing the expert, the postgraduate and the barrister with a $O$ feast of gargantuan proportions with which only the expert might seek an occasional quibble-and $\mathrm{O}$ this is no mean feat in a field where observed facts and inferences have to withstand penetrating cross examination.

New inclusions of statutory law-the National $/$ o Insurance (Industrial Injuries) Act, on the legal $N$ responsibility of hospitals and nursing homes, on $N$ the implications of artificial insemination, on poi- $\mathbb{W}$ sons and other subjects, have supplanted older statutes, and Glaister has also revised a largece number of scientific sections-on fingerprints in $\frac{C}{\Phi}$ identity, on $\mathrm{Rh}$ sub-groups, on some of the newer $\stackrel{?}{?}$ poisons, D.D.T., beryllium and the like. The chemical tests have been relegated, properly we 